\title{
Effects of Tropical Cyclones on Ocean Heat Transport in a High-Resolution Coupled General Circulation Model
}

\author{
Enrico Scoccimarro, ${ }^{*}$ Silvio Gualdi, ${ }^{*},+$ Alessio Bellucci, ${ }^{+}$Antonella Sanna, ${ }^{+}$ \\ Pier Giuseppe Fogli, ${ }^{+}$Elisa Manzini, ${ }^{,+},+\#$ Marcello Vichi, ${ }^{*},+$ PaOlo Oddo, ${ }^{*}$ \\ AND ANTONIO NAVARRA*,+ \\ * Istituto Nazionale di Geofisica e Vulcanologia, Bologna, Italy \\ ${ }^{+}$Centro Euro-Mediterraneo per i Cambiamenti Climatici, Bologna, Italy
}

(Manuscript received 4 October 2010, in final form 17 February 2011)

\begin{abstract}
In this paper the interplay between tropical cyclones (TCs) and the Northern Hemispheric ocean heat transport (OHT) is investigated. In particular, results from a numerical simulation of the twentieth-century and twenty-first-century climates, following the Intergovernmental Panel on Climate Change (IPCC) twentiethcentury run $(20 \mathrm{C} 3 \mathrm{M})$ and A1B scenario protocols, respectively, have been analyzed. The numerical simulations have been performed using a state-of-the-art global atmosphere-ocean-sea ice coupled general circulation model (CGCM) with relatively high-resolution (T159) in the atmosphere. The CGCM skill in reproducing a realistic TC climatology has been assessed by comparing the model results from the simulation of the twentieth century with available observations. The model simulates tropical cyclone-like vortices with many features similar to the observed TCs. Specifically, the simulated TCs exhibit realistic structure, geographical distribution, and interannual variability, indicating that the model is able to capture the basic mechanisms linking the TC activity with the large-scale circulation. The cooling of the surface ocean observed in correspondence of the TCs is well simulated by the model. TC activity is shown to significantly increase the poleward OHT out of the tropics and decrease the poleward OHT from the deep tropics on short time scales. This effect, investigated by looking at the 100 most intense Northern Hemisphere TCs, is strongly correlated with the TC-induced momentum flux at the ocean surface, where the winds associated with the TCs significantly weaken (strengthen) the trade winds in the $5^{\circ}-18^{\circ} \mathrm{N}\left(18^{\circ}-30^{\circ} \mathrm{N}\right)$ latitude belt. However, the induced perturbation does not impact the yearly averaged OHT. The frequency and intensity of the TCs appear to be substantially stationary through the entire 1950-2069 simulated period, as does the effect of the TCs on the OHT.
\end{abstract}

\section{Introduction}

Tropical cyclones (TCs) originate over the tropical oceans and are mainly fueled by heat transfer from the ocean (Emanuel 2003). The wind activity associated with tropical cyclones is responsible for two atmosphere-ocean feedbacks (Bender et al. 1993): the first feedbackpositive-is driven by the latent heat associated with the strengthened evaporation rate and leads to an increase of the available energy for TC development (Riehl 1950;

\footnotetext{
\# Current affiliation: Max Planck Institute for Meteorology, Hamburg, Germany.

Corresponding author address: Enrico Scoccimarro, CMCC, Via Aldo Moro 44, 40127 Bologna, Italy.

E-mail: scoccimarro@bo.ingv.it
}

Kleinschmidt 1951); the second feedback-negative-is due to the cold water upwelling induced by the increased wind stress at the ocean surface and by the shear-induced mixing at the base of the mixed layer (Jansen et al. 2010). The second feedback is responsible for a significant cooling of the sea surface (Price 1981; Black 1983; Bender and Ginis 2000). The sea surface temperature (SST) feedback generally leads to a weakening of the cyclone intensity due to the reduction of the total heat flux into the atmosphere (Schade and Emanuel 1999; Chan et al. 2001). The SST reduction beneath a moving TC is mainly due to the entrainment from the deep ocean, while surface flux interactions play a minor role (Price 1981). The ocean response to moving TCs has been studied using coupled numerical experiments (Chang and Anthes 1979; Sutyrin and Khain 1979; Schade and Emanuel 1999), and there is growing evidence that the TC activity plays a role in the thermodynamics of the ocean. The TC-induced upwelling leaves 
cold wakes that are restored to normal conditions over a period of weeks as result of a net enthalpy flux from the atmosphere to the ocean column, through the sea surface. This net heating is balanced by a poleward ocean heat transport (OHT), linking the TC activity to the largescale thermohaline circulation (Emanuel 2001). There is, therefore, evidence that TCs can transfer a significant amount of heat (Emanuel 2001; Sriver and Huber 2007; Pasquero and Emanuel 2008) and momentum (Liu et al. 2008) into the ocean, suggesting that they might play a role in the global climate system.

Recent studies estimated vertical ocean heat pumping by TC mixing ranging from $\sim 0.26$ to $0.4 \mathrm{PW}$ (Sriver and Huber 2010). Despite these values being considerably smaller if compared to the $1.4 \mathrm{PW}$, as suggested by Emanuel (2001), if heat anomalies generated by TCs propagate poleward, then these values might contribute far more than $10 \%$ of the total OHT out of the tropics. Conversely, new observation-based studies (Jansen et al. 2010) suggest that only the mixing events that penetrate beneath the seasonal thermocline contribute to net oceanic heat convergence. Shallow anomalies are likely to be smoothed out by seasonal variations in the thermocline and eventually lost back to the atmosphere.

Idealized modeling approaches prescribing TCs effects (Hu and Meehl 2009; Fedorov et al. 2010) have been used to investigate the relationship between TC activity and climate. As suggested by Sriver (2010) and Sriver et al. (2010b), these methods are not sufficient to reflect the full extent of TC-induced ocean-atmosphere feedbacks. The use of a "hurricane permitting" coupled general circulation model (CGCM) of the global atmosphere and ocean may serve as an advanced tool to investigate the interplay between TCs and the ocean.

In this work, results from a CGCM with a highresolution (T159) atmospheric component are analyzed to estimate the contribution of tropical cyclones to the global ocean heat transport budget. The primary aim of this analysis is to investigate the TC-induced ocean heat transport $\left(\mathrm{OHT}_{\mathrm{TC}}\right)$, focusing on the last part of the twentieth century. The second aim is to study the effects of climate change on the TC activity and $\mathrm{OHT}_{\mathrm{TC}}$ by using a greenhouse gas emission scenario for the twenty-first century.

This article is organized as follows. The model is described in section $2 \mathrm{a}$. The climate simulation design is outlined in section $2 b$, while section $2 c$ describes the reference data used to validate these simulations. Section $2 \mathrm{~d}$ illustrates the TC detection method. The simulated tropical climate and the ability to represent TCs has been deeply described in section $3 \mathrm{a}$ because of the introduction of higher resolution in the atmospheric component with respect to previous works (Gualdi et al.
2008). The new method used for TC detection suggested by the Tropical Cyclone Climate Model Intercomparison Project (TCMIP) is also described in the same section. Section $3 \mathrm{~b}$ assesses the interplay between TCs and the ocean thermal structure at the monthly/weekly time scale. Section $3 c$ analyses the connection between $\mathrm{TC}$ activity and mean OHT on longer time scales. The effects of global warming on TC activity and $\mathrm{OHT}_{\mathrm{TC}}$ are described in section $3 \mathrm{~d}$. Section 4 summarizes the major results of this work.

\section{Model, simulations, and methodology}

\section{a. The model}

The model employed in this work is the Centro EuroMediterraneo per i Cambiamenti Climatici (CMCC_ MED; Gualdi et al. 2010, manuscript submitted to Climate Dyn.) coupled atmosphere-ocean general circulation model (CMCC_MED), which has been implemented and developed in the framework of the European Climate Change and Impact Research: The Mediterranean Environment (CIRCE; http://www.circeproject.eu/) Project. For this reason, the model has a focus on the Mediterranean region, and a very high-resolution model of the Mediterranean Sea has been introduced as a component of the coupled atmosphere-ocean system to better represent the dynamical processes that characterize this region. The present study focuses on the ability of the model to simulate an important feature of the tropical climate. Therefore, a secondary objective of this study is to contribute to the validation of the CMCC climate model on a global scale. The model is an evolution of the Istituto Nazionale di Geofisica e Vulcanologia (INGV) Scale Interaction Experiment [SINTEX-G (SXG)] Gualdi et al. 2008; Bellucci et al. 2008) and the CMCC Earth System Model (Fogli et al. 2009; Vichi et al. 2011). In CMCC_MED, the ocean component is simulated through a coarse-resolution global ocean model and a high-resolution eddy-permitting model of the Mediterranean Sea. This second ocean model is hard coded into CMCC MED, and this feature is not relevant for the aim of this paper.

The global ocean component is OPA 8.2 (Madec et al. 1998), in its ORCA2 global configuration. The horizontal resolution is $2^{\circ} \times 2^{\circ}$ with a meridional refinement near the equator, approaching a minimum $0.5^{\circ}$ grid spacing. The model has 31 vertical levels, 10 of which lie within the upper $100 \mathrm{~m}$. ORCA2 also includes the Louvain-La-Neuve (LIM) model for the dynamics and thermodynamics of sea ice (Fichefet and MoralesMaqueda 1999). Ocean physics includes a free-surface parameterization (Roullet and Madec 2000) and the 

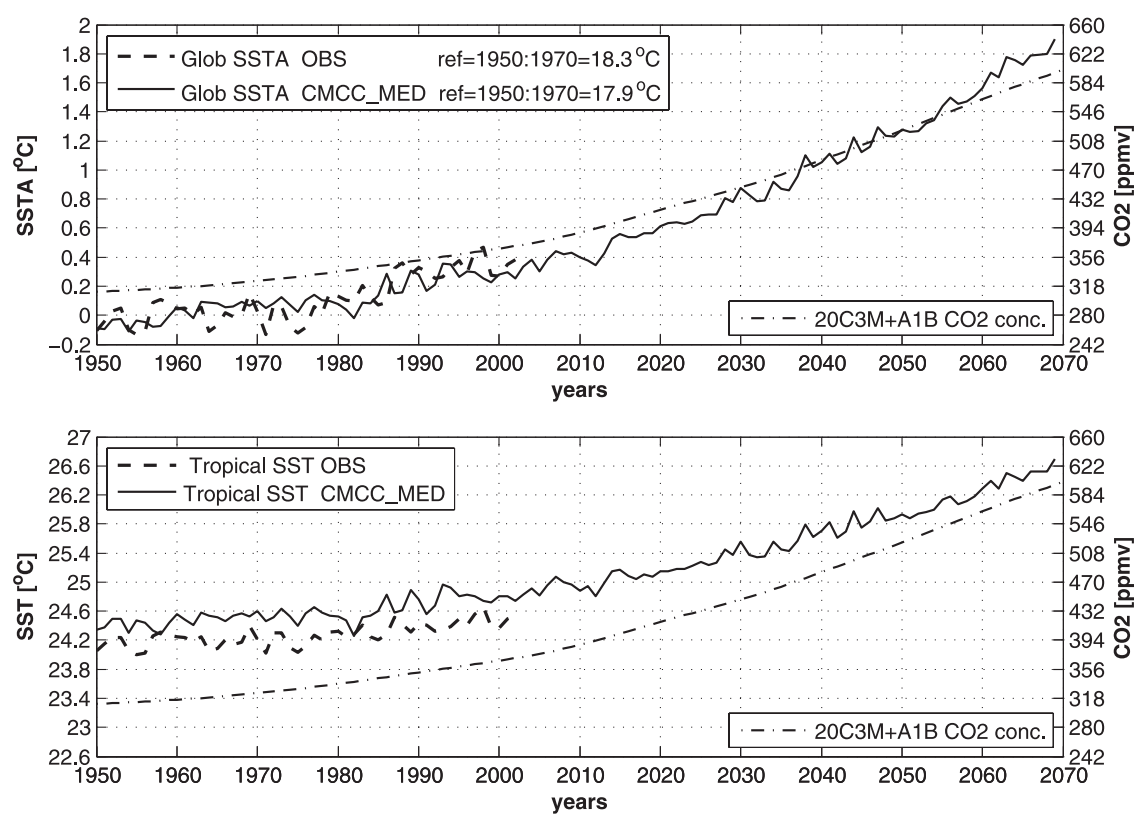

FIG. 1. (top) Prescribed $\mathrm{CO}_{2}$ concentration (dotted-dashed line) time series and SSTA, globally averaged, from the model (solid line) and the observation (dashed line). Anomaly is computed with respect to the period 1950-70. (bottom) Tropical averaged SST from the model (solid line) and observation (dashed line) is shown. $\mathrm{CO}_{2}$ concentration (dotted-dashed line) time series is the same in both panels.

Gent and McWilliams (1990) scheme for isopycnal mixing. For more details about the ocean model and its performance, readers are referred to Madec et al. (1998; www.lodyc.jussieu.fr/opa/).

The Mediterranean Sea model (Oddo et al. 2009) is a regional configuration of Nucleus for European Modelling of the Ocean (NEMO) (Madec 2008), with a $1 / 16^{\circ}$ horizontal resolution and 71 levels along the vertical.

The atmospheric model component is ECHAM5 (Roeckner et al. 2003) with a T159 horizontal resolution, corresponding to a Gaussian grid of about $0.75^{\circ} \times 0.75^{\circ}$. This configuration has 31 hybrid sigma-pressure levels in the vertical and top at $10 \mathrm{hPa}$. The parameterization of convection is based on the mass flux concept (Tiedtke 1989), modified following Nordeng (1994). Moist processes are treated using a mass conserving algorithm for the transport (Lin and Rood 1996) of the different water species and potential chemical tracers. The transport is resolved on the Gaussian grid. A more detailed description of the ECHAM model performance can be found in Roeckner et al. (2006).

The communication between the atmospheric model and the ocean models is carried out with the Ocean Atmosphere Sea Ice Soil version 3 (OASIS3) coupler (Valcke 2006). Every $160 \mathrm{~min}$ (coupling frequency), heat, mass, and momentum fluxes are computed and provided to the ocean model by the atmospheric model.
SST and sea surface velocities are provided to the atmospheric model by both ocean models. The global ocean model also provides sea ice cover and thickness to the atmospheric model. The relatively high coupling frequency adopted allows an improved representation of the interaction processes occurring at the air-sea interface. No flux corrections are applied to the coupled model.

\section{b. The climate simulations}

CMCC_MED has been implemented to perform climate scenario experiments. Here we present results from a climate simulation covering the period 1950-2069, following the Intergovernmental Panel on Climate Change (IPCC) 20C3M protocol for the twentieth century and the A1B scenario for the 21st century (http://www-pcmdi. llnl.gov/ipcc/about $\left.\_i p c c . p h p\right)$. In Fig. 1 the $\mathrm{CO}_{2}$ concentration time series for the period 1950-2069 is shown: by the end of 2069, the carbon dioxide concentration has approximately doubled compared with the 1950 value. The simulation starts from an equilibrium state obtained by integrating the model for $200 \mathrm{yr}$ with greenhouse gas (GHG) concentrations corresponding to 1950 s conditions. The equilibrium is characterized by a stable meridional overturning circulation at about $14 \mathrm{~Sv}(1 \mathrm{~Sv} \equiv$ $106 \mathrm{~m}^{3} \mathrm{~s}^{-1}$ ) in the last 50 years of the spinup (not shown). 


\section{c. Reference data}

The capability of the model to simulate the observed SST and precipitation has been assessed using the Met Office Hadley Centre Sea Ice and Sea Surface Temperature (HadISST) dataset (Rayner et al. 2003) and the dataset produced by Xie and Arkin (1997). To validate the TC distribution and climatology provided by the model, the results have been compared with observational datasets from the National Hurricane Center (NHC) and the U.S. Joint Typhoon Warning Center (JTWC). In the rest of the paper we will refer to these data as observations. The analyses have been performed using 6-hourly averaged atmospheric model outputs and daily averaged ocean model outputs.

\section{d. Simulated occurrence of TCs: Detection method}

An overview of the criteria adopted for TC detection in atmospheric analyses and model simulations is given in Walsh (1997) and Chauvin et al. (2006), respectively. The occurrence method used in this work is a tracking technique looking for individual TCs based on objective criteria for the identification of specific atmospheric conditions. In particular, TCs are identified and tracked as surface pressure minima, with a center of high relative vorticity; the latter is diagnosed on the 850 -hPa surface, warm core, and maximum wind at the surface (exceeding a threshold value). The tracking method is different from the one presented in Gualdi et al. (2008) to be consistent with the TCMIP (http://www.earthsci.unimelb. edu.au/ kwalsh/tcmip_index.html). Specifically, we used the Commonwealth Scientific and Industrial Research Organisation (CSIRO) method developed under the framework of that project, which implies that a model TC is active over a grid point if the following conditions are satisfied:

1) Relative vorticity at $850 \mathrm{hPa}$ is larger than $1 \times$ $10^{-5} \mathrm{~s}^{-1}$

2) There is a relative surface pressure minimum, and the surface pressure anomaly, compared to a surrounding area with a radius of $350 \mathrm{~km}$, is larger than $2 \mathrm{hPa}$

3) In a region with a radius of $350 \mathrm{~km}$ around the grid point considered, there is a grid point where the maximum surface wind velocity is larger than $15.5 \mathrm{~m} \mathrm{~s}^{-1}$

4) Wind velocity at $850 \mathrm{hPa}$ is larger than wind velocity at $300 \mathrm{hPa}$

5) The sum of temperature anomalies at 700, 500, and $300 \mathrm{hPa}$ is larger than $1 \mathrm{~K}$, where anomalies are defined as the deviation from a spatial mean computed over a region with a radius of $350 \mathrm{~km}$

6) The above-mentioned conditions persist for at least $24 \mathrm{~h}$ (corresponding to four time steps of the model output)
The maximum surface wind velocity (WIMAX) mentioned in condition 3 is not averaged over $6 \mathrm{~h}$, but it is defined as an instantaneous value. This condition is resolution dependent and it has been chosen following Walsh et al. (2007). For a complete discussion of these criteria and their sensitivity to the parameters used the reader is addressed to Walsh (1997) and Walsh et al. (2007).

\section{Results}

\section{a. TCs as simulated by the model}

This section summarizes the main aspects of model mean climate and systematic error compared with observations. A more detailed analysis of the model performance and a more thorough comparison with the observations is given in Gualdi et al. (2010, manuscript submitted to Climate Dyn.).

In terms of SST, the model reproduces well the global trend observed during the second half of the twentieth century (Fig. 1, top panel). The simulated SST global mean averaged over the period $1950-1970$ is $17.9^{\circ} \mathrm{C}$, whereas the mean value from the observations for the same period is $18.3^{\circ} \mathrm{C}$. Therefore, the model exhibits a global SST bias of about $-0.4^{\circ} \mathrm{C}$, which is reduced to $+0.2^{\circ} \mathrm{C}$ in the tropics (Fig. 1, bottom panel).

In the observations the period of maximum TC activity is the extended summer, from June to October (JJASO) in the Northern Hemisphere $(\mathrm{NH})$ and from December to April (DJFMA) in the Southern Hemisphere (SH). Figure 2 shows the mean JJASO (top panels) and DJFMA (bottom panels) tropical SST as obtained from the model (right panels) and observations (left panels) for the period 1970-99 (20C). The SST bias shown by CMCC_MED exhibits features that are common to many state-of-theart climate models (Randall et al. 2007). During the JJASO period, there is a pronounced cold bias covering the region from $25^{\circ}$ up to $40^{\circ} \mathrm{N}$ in the Atlantic and West Pacific. Dark-gray-shaded patterns indicate the regions where the cold bias is larger than $1^{\circ} \mathrm{C}$. In the regions of $\mathrm{TC}$ genesis, the modeled temperature bias is generally smaller than $1^{\circ} \mathrm{C}$. Figure 3 shows the mean JJASO (top panels) and DJFMA (bottom panels) precipitation as obtained from the model (right panels) and observations (left panels) for the $20 \mathrm{C}$ period. In the Pacific Ocean, the model overestimates the rainfall, tending to produce a double ITCZ, especially during northern winter. In the Indian Ocean during JJASO, there is a northward shift of the rainfall pattern and a westward shift during DJFMA. In the Atlantic Ocean, the model precipitation is realistic during JJASO and there is a southward shift of the rainfall pattern if compared to the observations during DJFMA, consistent with the warm bias diagnosed in this region (Fig. 2). 

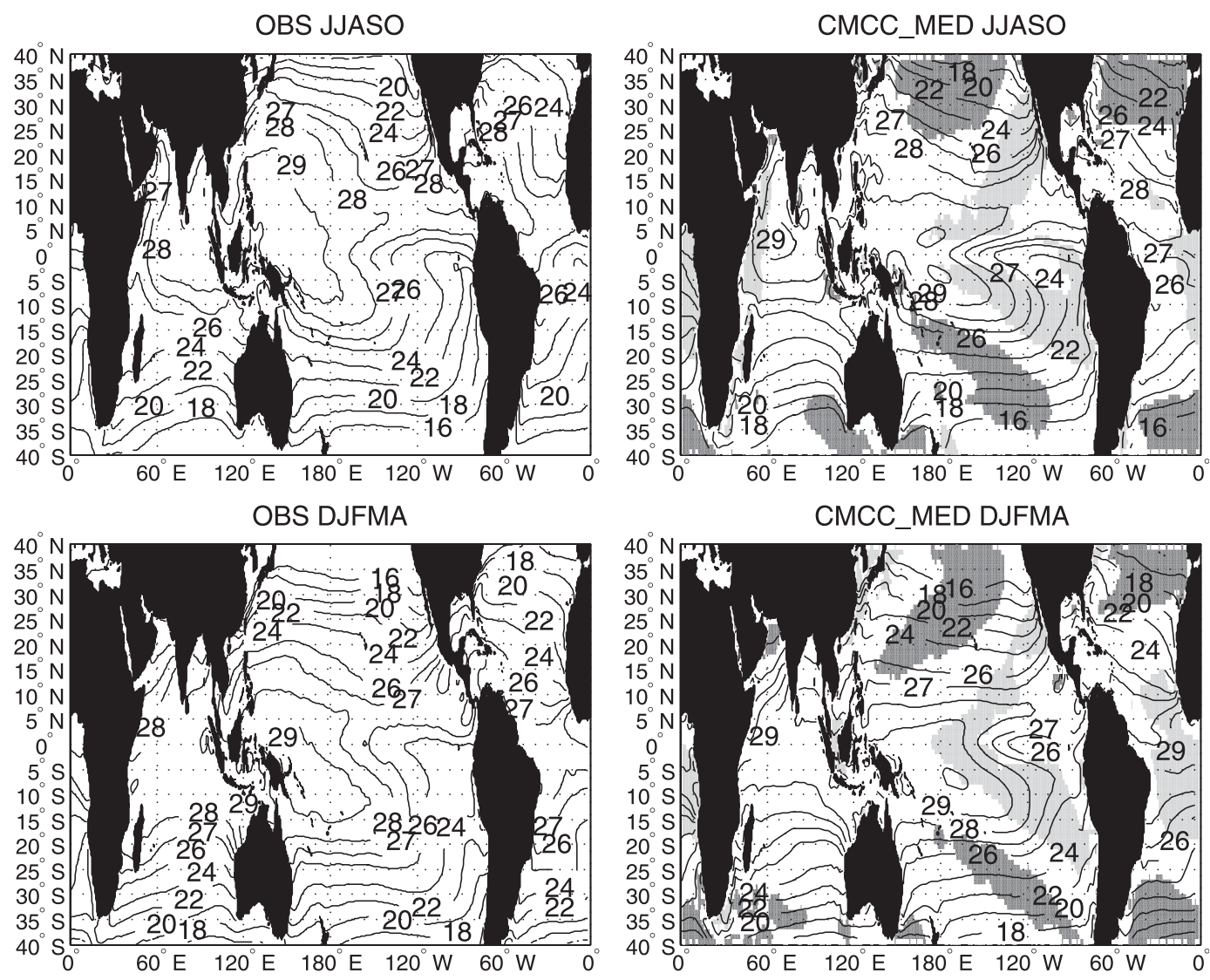

FIG. 2. Seasonal means of SST as obtained from the (left) observations and (right) model. (top) Extended NH summer means JJASO; (bottom) extended SH summer means DJFMA. SST contours are $2^{\circ}$ from $16^{\circ}$ to $26^{\circ}$ and $1^{\circ}$ from $26^{\circ}$ to $30^{\circ} \mathrm{C}$. Light (dark)-gray-shaded patterns indicate regions where the SST difference between model and observations is larger (smaller) than $1(-1)^{\circ} \mathrm{C}$.

The ability of the model to simulate TC location and frequency has been assessed comparing regionally the model results with observations. The geographical distribution of the TC formation positions is shown in Fig. 4. In the observations (Fig. 4a), there are four distinct regions of TC formation in the tropics of the Northern Hemisphere-the northern Indian Ocean (NI), the western North Pacific (WNP), the eastern North Pacific (ENP), and the North Atlantic (ATL) - and three regions in the Southern Hemisphere-the southern Indian Ocean (SI), the ocean north of Australia (AUS), and the South Pacific (SP). Based on these regions of TC genesis, and following Camargo et al. (2004), we define seven basins (see the boxes in Fig. 4) that will be used to delimit the different areas of TC activity. The model reproduces well the known patterns of TC genesis (Fig. 4), except for the southern Atlantic area, where the model generates some TCs during the considered period, though only one TC has been reported in this region, in March 2004 (Pezza and Simmonds 2005). This overestimation in TC counts is probably related to the warm SST bias that reaches $2^{\circ} \mathrm{C}$ over the southern Atlantic region (Fig. 2). On average, the number of simulated TCs detected over the entire globe and over the $20 \mathrm{C}$ period is $80.2 \mathrm{TCs}$ per year, with a standard deviation of 7.5 TCs per year. Compared with the observed values (93.8 TCs per year with a standard deviation of 10.9 TCs per year), this represents improved skill in simulating the annual number of TCs and its variability if compared to atmospheric general circulation models (GCMs) (Camargo et al. 2004) and coupled GCMs (Gualdi et al. 2008) characterized by lower spatial resolution. In a current climate simulation performed with a 20-km-mesh global atmospheric model, Oouchi et al. (2006), tuning their detection method to better represent the observed TC numbers, found 78.3 TCs per year with a standard deviation of 8.4 TCs per year. Therefore, the capability of CMCC_MED to represent TC genesis is comparable with results obtained by higher-resolution GCMs.

The $15 \%$ deficiency in the detected number of global TCs is mainly due to the underestimation of simulated TCs in the ATL and ENP regions (Fig. 4). This is more 
OBS JJASO

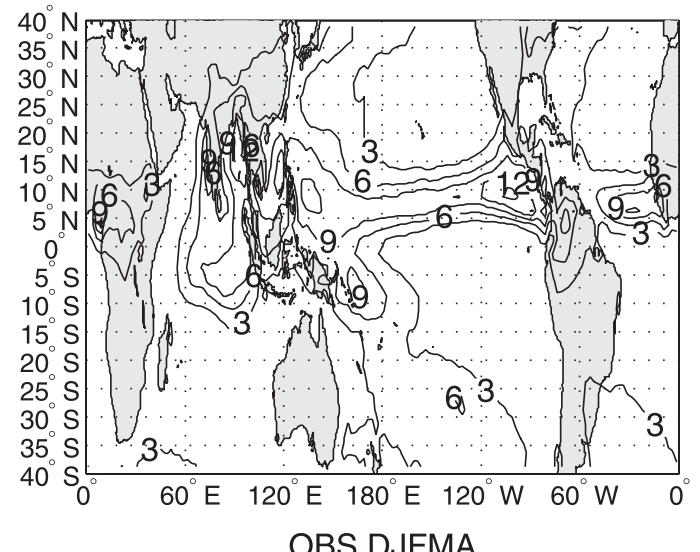

OBS DJFMA

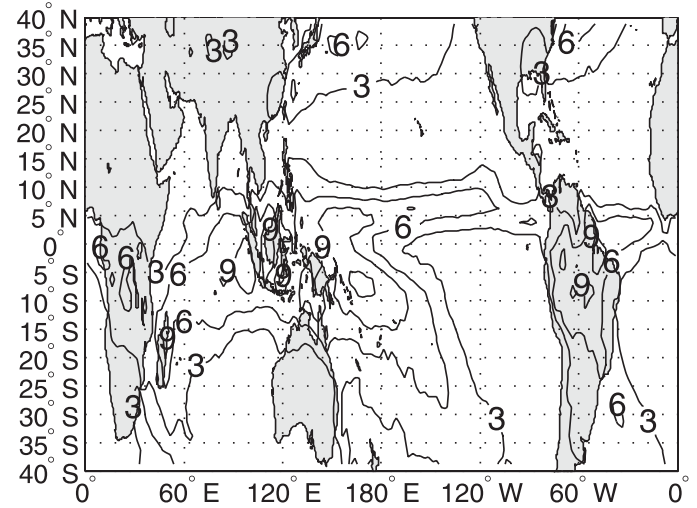

CMCC MED JJASO
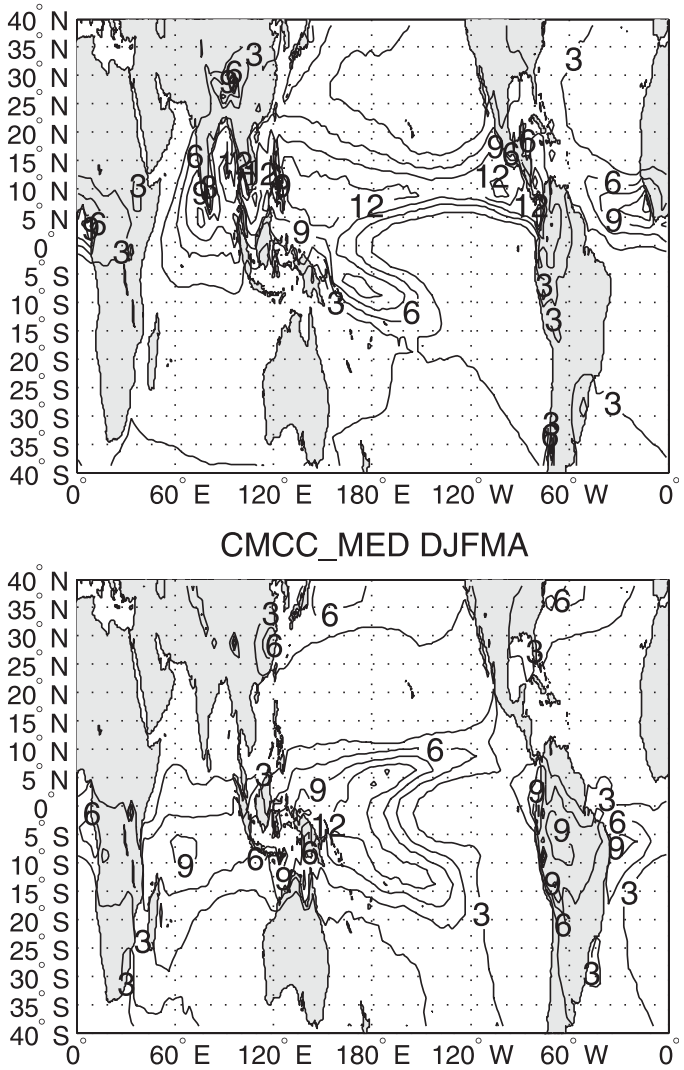

FIG. 3. Seasonal means of total precipitation as obtained from the (left) observations and (right) model. (top) Extended NH summer means JJASO; (bottom) extended SH summer means DJFMA. Precipitation contours are $3 \mathrm{~mm} \mathrm{day}^{-1}$ and range from 3 to $15 \mathrm{~mm} \mathrm{day}^{-1}$.

evident in Fig. 5, where the box plots of the TC numbers are shown region by region, for the model and observations. This discrepancy is partly offset in the total count by the overestimation of the TC numbers in the SP region.

The ability of the model to reproduce the TC structure is investigated by computing the composites of total precipitation and $10-\mathrm{m}$ wind intensity over the $100 \mathrm{most}$ intense TCs in the NH (Fig. 6, top panels) and SH (Fig. 6 , bottom panels).

Here, wind intensity refers to the simulated maximum wind speed (WIMAX) reached near the surface (10 m above the surface). The atmospheric model time step is 4 min; therefore, we can consider WIMAX as a "4-min sustained wind speed." The WIMAX over the 100 most intense TCs varies from 27 to $39 \mathrm{~m} \mathrm{~s}^{-1}$ in the NH and from 26 to $35 \mathrm{~m} \mathrm{~s}^{-1}$ in the SH. Following the National Oceanic and Atmospheric Administration (NOAA)'s National Weather Service (2002), a hurricane is "a tropical cyclone in which the maximum 1-min sustained surface wind is $64 \mathrm{kt}\left(33 \mathrm{~m} \mathrm{~s}^{-1}\right)$ "; therefore, our results indicate that the CMCC_MED climate model is able to simulate TCs with hurricane intensity. About $10 \%$ of the 100 TCs in the $\mathrm{NH}$ and $\mathrm{SH}$ used to compute the composites in Fig. 6 belong to the hurricane class.

The wind and precipitation patterns shown in Fig. 6 suggest that the simulated TCs have a realistic structure, consistent with previous GCM results (Bengtsson et al. 1995; Chauvin et al. 2006; Gualdi et al. 2008). The horizontal resolution is still too coarse to represent the "TC eye" in the precipitation pattern (Fig. 6, left panels), but the 10-m wind pattern (Fig. 6, right panels) shows a sharp weakening with a distance from the center of two model grid points (about $160 \mathrm{~km}$ ) as expected. Moreover, the right-front sector of the $10-\mathrm{m}$ wind maximum is consistent with observations (Gray 1979; Willoughby et al. 1982). In the NH, moving from east to west, the right-front sector is the region from the northwest to the northeast, where the composite wind maximum is located (Fig. 6, top right panel). A secondary wind maximum toward the southeast in the same pattern is due to the poleward component of the TC tracks.

In the model the strongest wind velocities are farther away from the eye. Also this model error is presumably a consequence of the relatively coarse horizontal resolution 

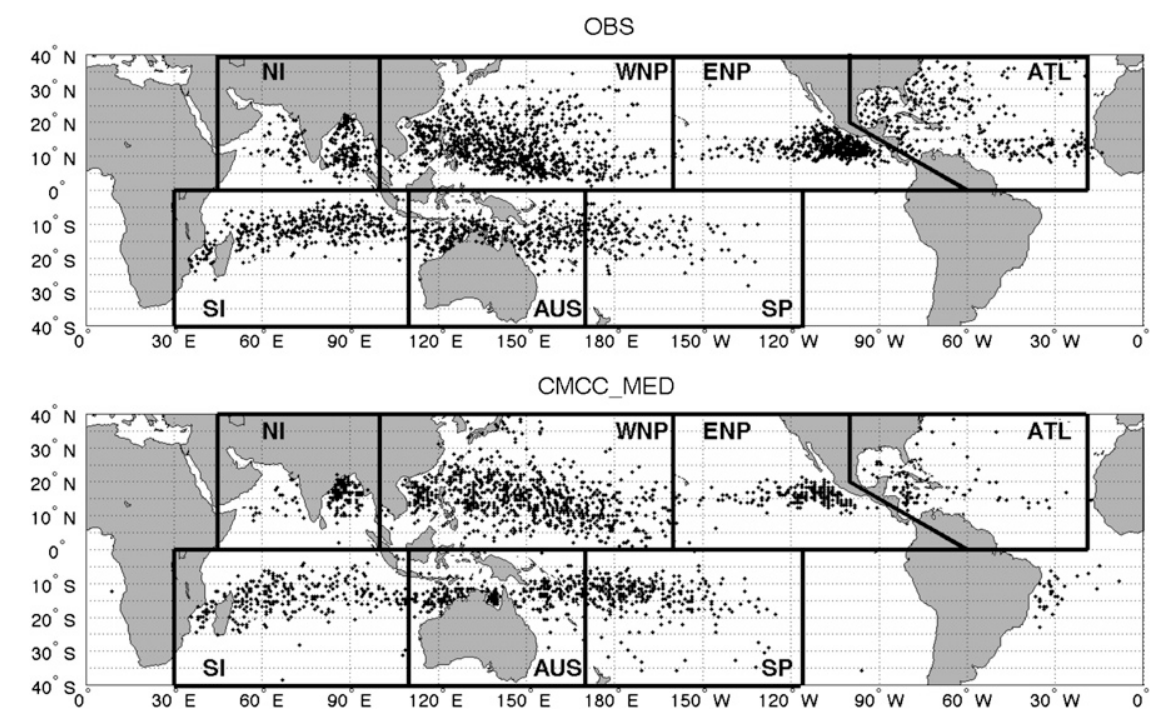

FIG. 4. Distribution of the TC track starting points for the period 1970-99 for the (top) observations and (bottom) model. Each point corresponds to the geographical location of a TC at the time of its first detection. Following Camargo et al. (2004), seven regions of TC genesis have been defined (delimited by thick black lines in figure).

of the atmospheric component, insufficient to represent the detailed TC structure (Bengtsson et al. 1995). The composite shown in Fig. 6 smoothes out the simulated maximum TC wind speeds because the location of the maximum winds is slightly different in each storm.

\section{b. The effect of TCs on air-sea interaction}

In the present section, the effects of TC transit on the surface ocean thermal state and associated heat transport are analyzed over the time scale of weeks. The composite of the SST anomaly (SSTA) induced by the 100 most intense TCs over the region where the maximum TC intensity (WIMAX) is reached has been calculated. The anomaly is computed as the difference between the SST over a time window of two days around the occurrence of the WIMAX as follows:

$$
\operatorname{SSTA}=\operatorname{SST}\left(t_{\text {wimax }}+\Delta t_{42}\right)-\operatorname{SST}\left(t_{\text {wimax }}-\Delta t_{6}\right),
$$

where $t_{\text {wimax }}$ is the time at which maximum WIMAX is reached; $\Delta t_{42}=42 \mathrm{~h}$ and $\Delta t_{6}=6 \mathrm{~h}$. Fixing the SST value before the WIMAX occurrence, $\operatorname{SST}\left(t_{\text {wimax }}-\Delta t_{6}\right)$, we computed the SSTA using different time lags after $t_{\text {wimax }}$ and found that a 2 -day period $\left(\Delta t_{42}+\Delta t_{6}\right)$ maximizes the anomaly. As shown in Fig. 7, the TC transit induces, on average, a sea surface cooling of about $0.35^{\circ} \mathrm{C}$ in the $\mathrm{NH}$ and $0.6^{\circ} \mathrm{C}$ in the $\mathrm{SH}$. The ocean region affected by surface cooling has a radius of about $400 \mathrm{~km}$ (five model grid points). The cooling mainly results from the entrainment of cold water from below, as revealed by the subsurface isotherms outcropping in the region where the TCs transit (not shown).

Because TCs vary greatly in location and strength, the thermal impact of an individual storm on the global ocean and the entire climate system is likely to be rather limited. Thus, to evaluate the integrated impact of TC activity on the ocean heat transport, the average anomaly of the transport has been calculated during the $N=100$ most intense simulated TC events as follows:

$$
\mathrm{OHT}_{\mathrm{TC}}=\frac{1}{N} \frac{1}{T} \sum_{i=1}^{N} \int_{\mathrm{t}_{\text {wimax }}-T / 2}^{\mathrm{t}_{\text {wimax }}+T / 2}\left(\mathrm{OHT}_{i}-\overline{\mathrm{OHT}_{\mathrm{i}}}\right) d t
$$

where $\mathrm{OHT}_{i}$ is the heat transport at each time step ( $d t=1$ day) corresponding to the $i$ th $\mathrm{TC}, \overline{\mathrm{OHT}_{i}}$ is the relative monthly climatology, and the integral is carried out over a $T=20$ days period centered at the day at which theCs, finally yielding a composite anomaly representative of the ocean heat transport induced by tropical cyclones.

The model representation of the annual $\mathrm{NH}$ meridional OHT, zonally averaged over 20C (Fig. 8, dotted line), is broadly consistent with existing OHT estimates. There is almost no ocean contribution north of $65^{\circ} \mathrm{N}$, and the 2-PW OHT maximum is consistent with the OHT values derived by Trenberth and Caron (2001) using National Centers for Environmental Prediction (NCEP) data, although in CMCC_MED the peak is shifted to the north by a few degrees. 

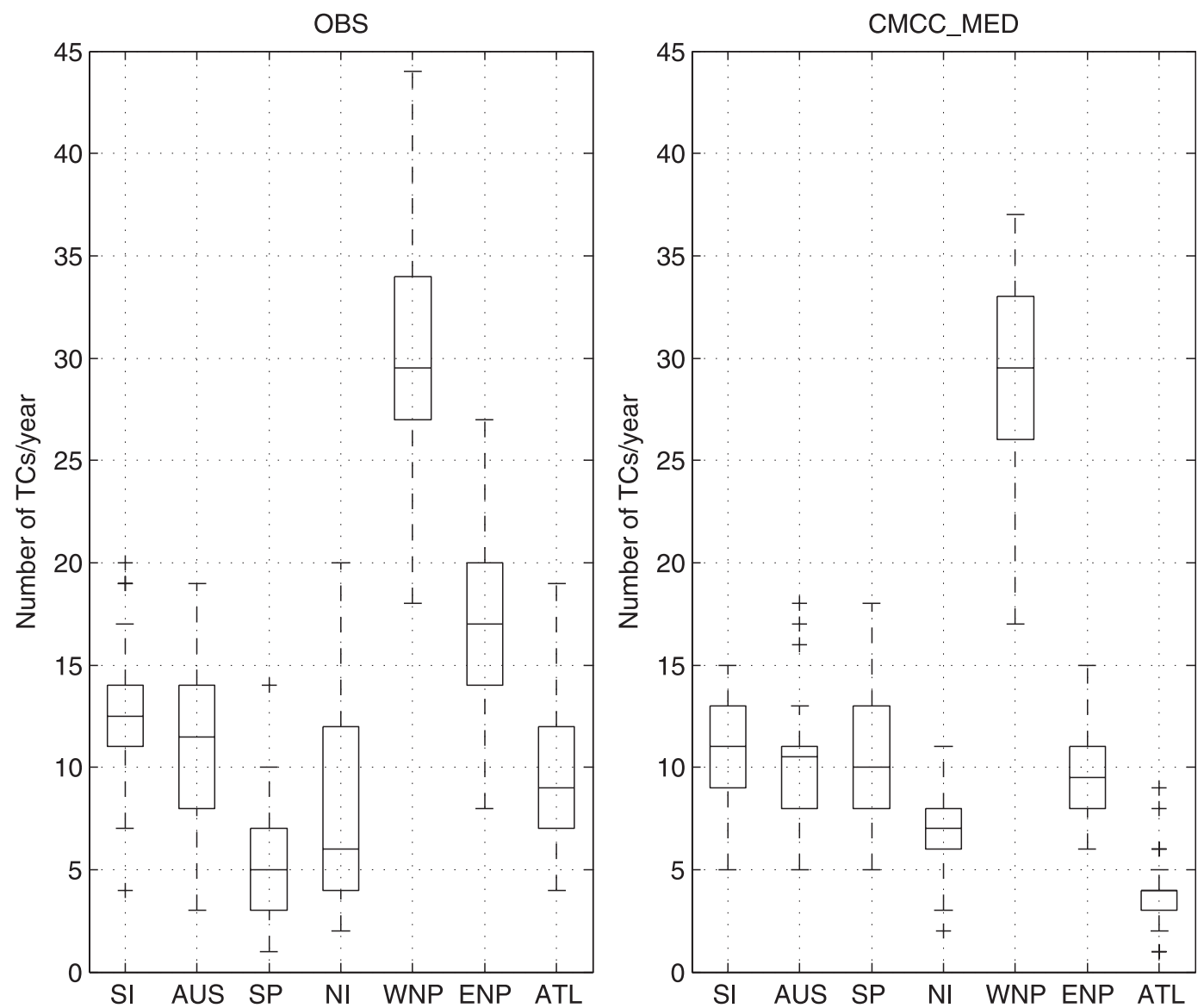

FIG. 5. Box plots of the number of TCs per year for the (left) observations and (right) model simulation. Reference period is 1970-99. Number of TCs ( $y$ axis) is plotted for each area of TC genesis ( $x$ axis) defined in Fig. 3. Box represents the interquartile (IQR) and contains $50 \%$ of the data; upper edge of the box represents the 75 th percentile [upper quartile (UQ)], while the lower edge is the 25th percentile [lower quartile (LQ)]. Horizontal lines within the box are the median. Vertical dashed lines indicate the range of the nonoutliers. Values indicated with the crosses are the outliers, i.e., values that are either larger than UQ +1.5IQR or lower than LQ - 1.5IQR.

The 100 TCs considered occurred between June and December (JJASOND). The mean JJASOND OHT shows negative values from the equator to about $13^{\circ} \mathrm{N}$ (Fig. 8, solid line), reflecting the seasonal meridional migration of the mean surface wind pattern (not shown). The $\mathrm{OHT}_{\mathrm{TC}}$ anomaly (Fig. 8, gray dashed line) shown by the model is negative from $0^{\circ}$ to $18^{\circ} \mathrm{N}$, with a -0.5 $\mathrm{PW}$ peak at $5^{\circ} \mathrm{N}$ representing, at this latitude, a $35 \%$ increase of the net equatorward OHT if compared to the JJASOND mean. Between $18^{\circ}$ and $40^{\circ} \mathrm{N}$ the anomaly becomes positive, reaching $0.1 \mathrm{PW}$ at $22^{\circ} \mathrm{N}$, corresponding to a $5 \%$ increase of the net poleward OHT at this latitude.

The effects of TCs on upper-ocean circulation are now investigated. To this aim the vertical $(\mathbf{W})$ and meridional (V) velocity anomalies due to the TCs transit were computed using the same composite methodology described for $\mathrm{OHT}_{\mathrm{TC}}$.
The $\mathbf{W}$ and $\mathbf{V}$ anomaly patterns reveal two overturning cells (Fig. 9). The positive anomaly of $\mathbf{W}$ induced by the TC activity in the tropics reaches $30 \%$ of the JJASOND averaged vertical velocity $\left(3 \times 10^{-5}\right.$ compared to $1 \times 10^{-4} \mathrm{~cm} \mathrm{~s}^{-1}$, not shown) at $100 \mathrm{~m}$ in depth and $15^{\circ} \mathrm{N}$ in latitude. In Fig. 9, the $\mathbf{W}$ anomaly is shown down to $500 \mathrm{~m}$, although it reaches $1000 \mathrm{~m}$ in depth in the model. The upwelling in the middle of the two overturning cells is balanced by downwelling south of $5^{\circ} \mathrm{N}$ and north of $30^{\circ} \mathrm{N}$.

The anomalous meridional overturning cells produce a northward shift of the background zonally averaged meridional mass transport, and the equatorward anomaly of $\mathbf{V}$ induced by the TC activity reaches $35 \%$ of the JJASOND averaged $\mathbf{V}$ at $20 \mathrm{~m}$ in depth and $8^{\circ} \mathrm{N}$ in latitude (Fig. 10). The anomaly of the meridional velocity appears to be consistent with the $\mathrm{OHT}_{\mathrm{TC}}$ anomaly (Fig. 8 ) because the zero crossing is located at about $18^{\circ} \mathrm{N}$ for 

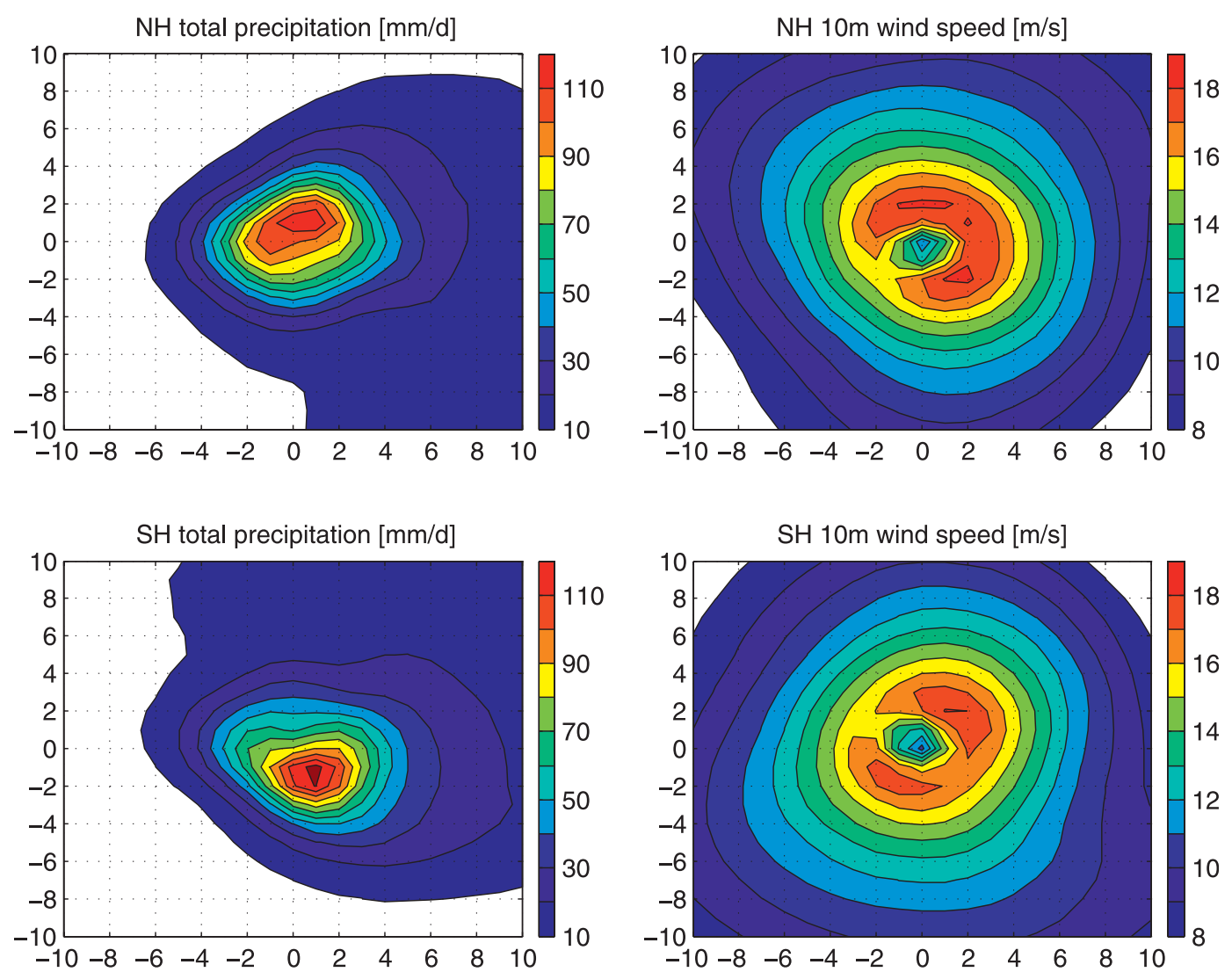

FIG. 6. Composite patterns of (left) total precipitation and (right) $10-\mathrm{m}$ wind speed associated with the 100 most intense TCs detected during 1970-99 by the model: (top) NH and (bottom) SH. Composites have been computed averaging the fields over the period of TC existence Lagrangian wise (i.e., following the TC in time and space) and over 100 events. (left) Precipitation and (right) $10-\mathrm{m}$ wind speed units are $\mathrm{mm} \mathrm{day}^{-1}$ and $\mathrm{m} \mathrm{s}^{-1}$, respectively. Model grid points (distance between two grid points $\sim 80 \mathrm{~km}$ ) from the TC core are shown on the $x$ and $y$ axes.

both the anomaly fields. The depth reached by the $\mathbf{V}$ anomaly (Figs. 9 and 10) suggests a wind-driven process associated with the Ekman layer dynamics. The zonally averaged TC-induced zonal momentum flux $\left(\mathrm{TAUX}_{\mathrm{TC}}\right)$ anomaly (Fig. 11, black solid line) and the $\mathrm{OHT}_{\mathrm{TC}}$ anomaly (Fig. 11, gray dashed line) reveal opposite phases around $18^{\circ} \mathrm{N}$. TCs thus increase the trade winds at higher latitudes $\left(18^{\circ}-30^{\circ} \mathrm{N}\right.$ band $)$ and weaken them at lower latitudes $\left(5^{\circ}-18^{\circ} \mathrm{N}\right.$ band). This effect on the tropical mean state modulates the energy transport into the ocean through an Ekman transport process that significantly impacts the OHT mean value in the Northern Hemisphere. This process can be identified only through a composite effect (i.e., over the 100 most intense simulated TCs). Single TCs do induce even stronger TAUX and OHT anomalies with zero crossing located at different latitudes. The probability density function of the meridional distribution of TC eyes during the considered TC days (not shown) exhibits a maximum at $18^{\circ} \mathrm{N}$; thus, at this latitude we expect to have the change of sign of the TC composite zonal winds. This is confirmed by the latitude at which TAUX $\mathrm{TC}_{\mathrm{TC}}$ and $\mathrm{OHT}_{\mathrm{TC}}$ anomalies cross the zero line (Fig. 11).

\section{c. Connection with the long-term OHT}

The approach described in section $3 \mathrm{~b}$ highlights how TCs affect the OHT on the order of weeks, addressing their immediate influence on heat fluxes. This time scale is too short to assess the TC role in the horizontal heat advection (Pasquero and Emanuel 2008). Furthermore, the weekly time scale is not sufficient to take into account the portion of TC-induced heat that remains into the ocean. In fact only the heat penetrating beneath the winter thermocline is not smoothed out by seasonal variation in the thermocline and lost back to the atmosphere in the following winter (Jansen et al. 2010). To quantify the permanent effect of TCs on the meridional OHT, the period 1970-89 has been also simulated with a modified version of CMCC_MED, designed to remove the TC effect on the ocean. In case of TC occurrence, the meridional 

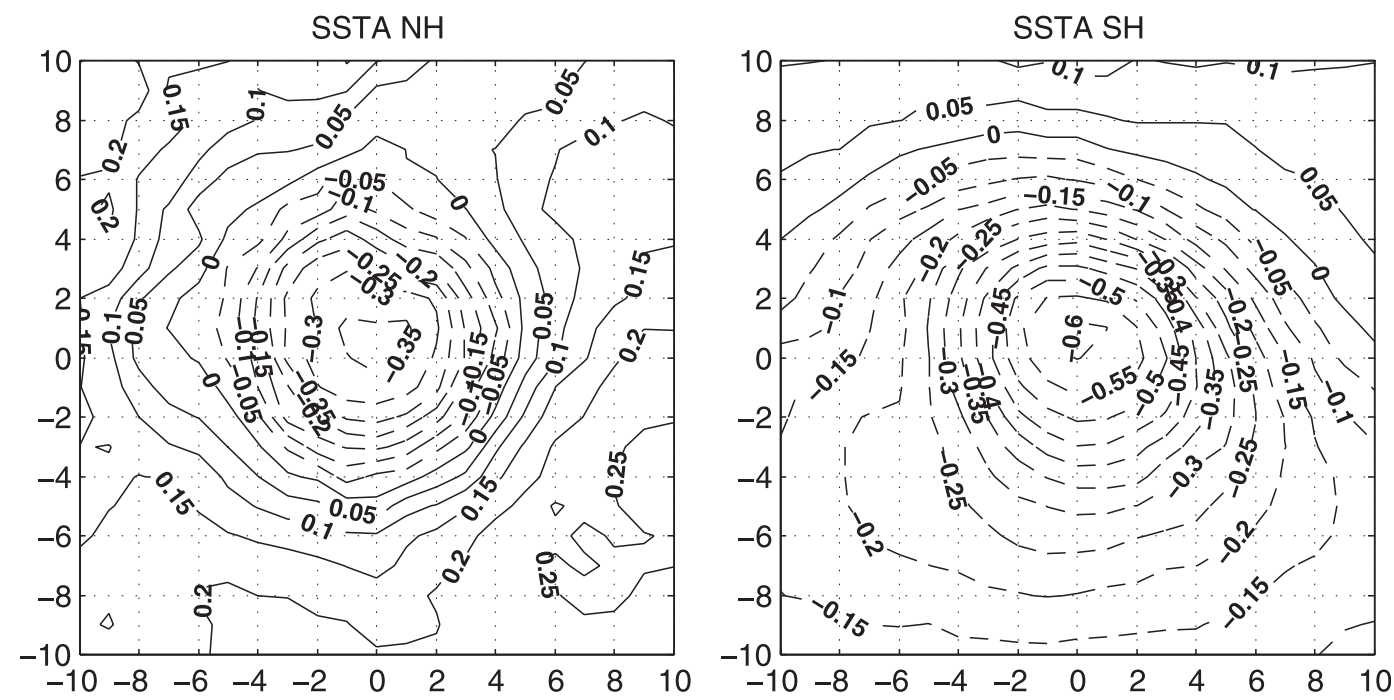

FIG. 7. Composite patterns of SSTA over the TC eye region. SST used to compute the anomaly are 6-hourly averaged fields. Anoamaly is computed over the 100 most intense TCs of the (left) NH and (right) SH during the period 1970-99. SSTA units are ${ }^{\circ} \mathrm{C}$. Model grid points as defined in Fig. 6.

and zonal wind stresses, sent from the atmospheric model to the ocean model, now have a maximum threshold. The threshold is computed considering $15.5 \mathrm{~m} \mathrm{~s}^{-1}$ as the surface wind velocity. This method inhibits the transfer of momentum induced by TCs to the ocean, leaving TCs free to develop in the atmospheric model. Therefore, TC-induced ocean-atmosphere feedbacks are suppressed although ocean and atmospheric models are still coupled.

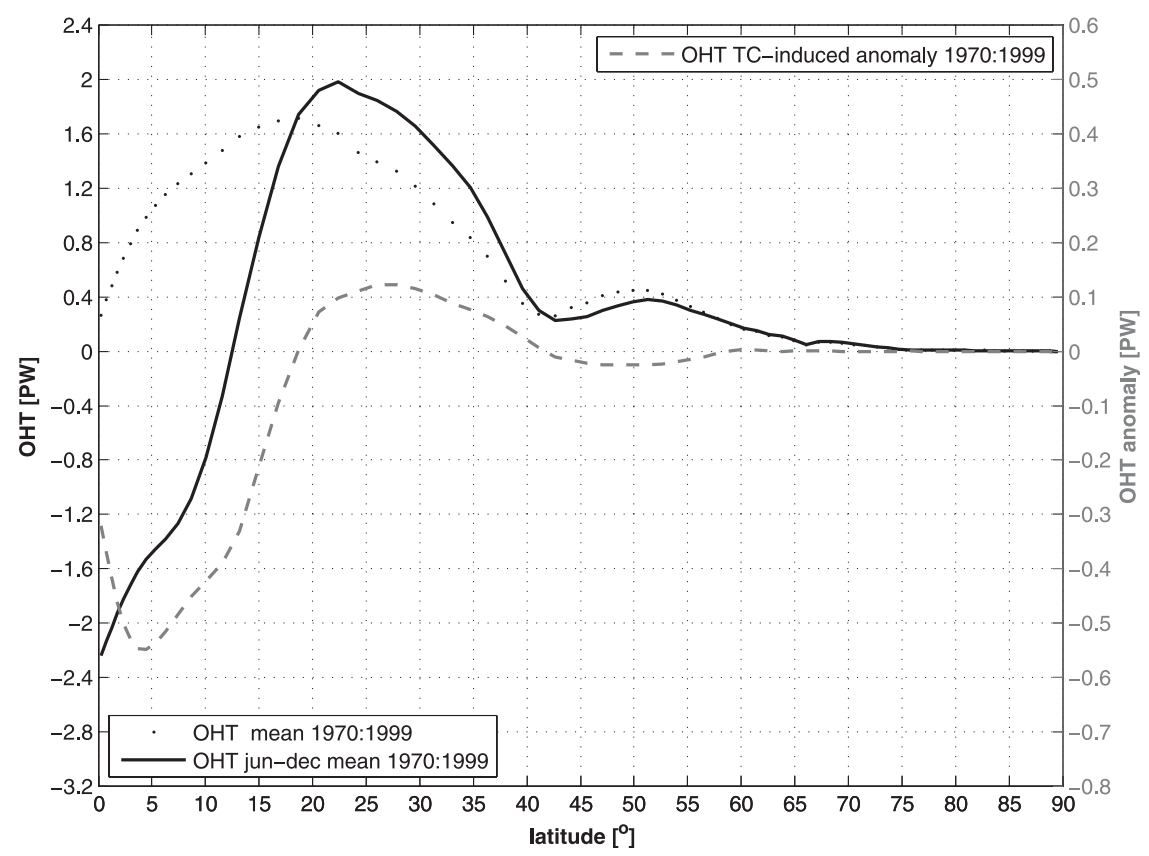

FIG. 8. NH OHT (dotted and solid lines) and NH OHT anomaly induced by TCs (dashed line). Anomalies have been computed for 20 days around the day of maximum intensity $\left(t_{\text {wimax }} \pm 10\right.$ days) of the TC compared to the climatological (1970-90) relative monthly value. Black dotted line is the annual mean OHT over the period 1970-99. Black solid line is the JJASOND mean OHT over the period 1970-99. Gray dashed line is the mean anomaly induced by the 100 most intense NH TCs over the period 1970-99 (as in Figs. 6 and 7). 


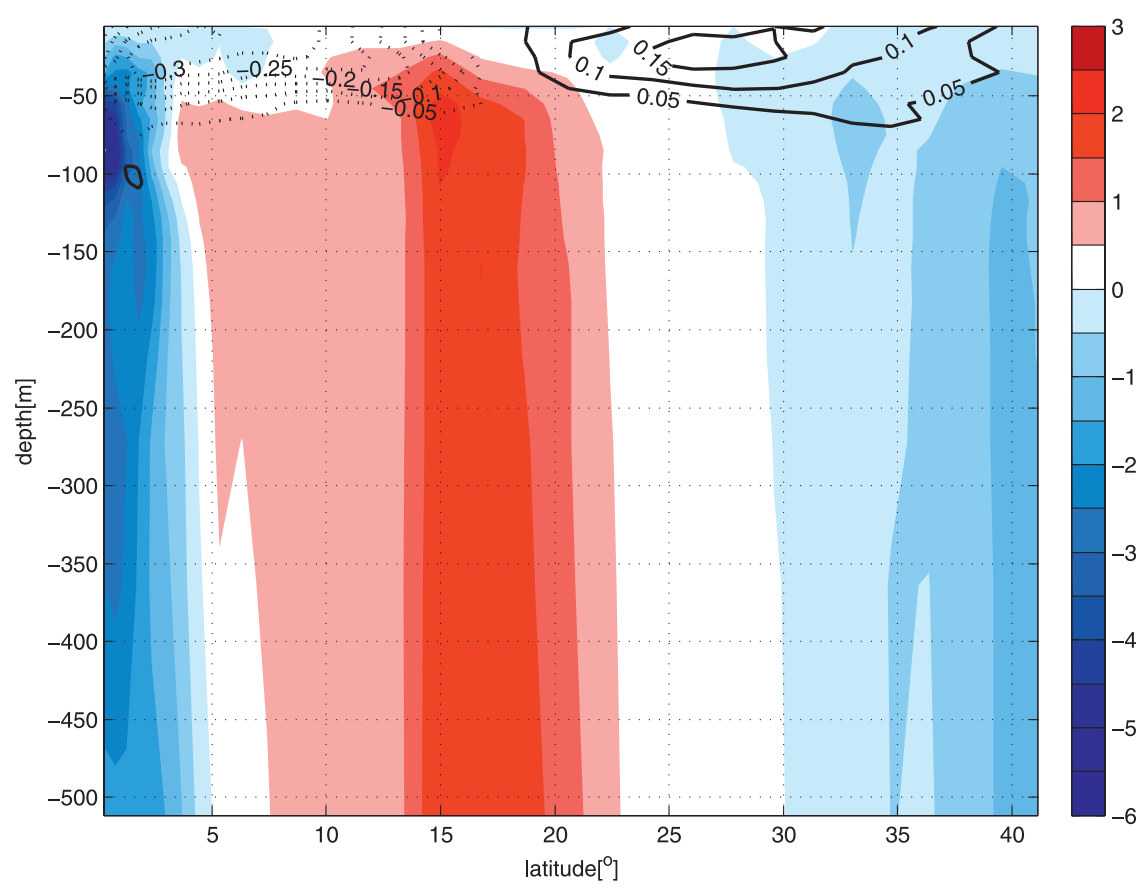

FIG. 9. Zonally averaged $\mathbf{W}$ anomaly computed over the period JJASOND 1970-99, scaled by a factor of $10^{5}$ (color). Contours are the TC-induced meridional $\mathbf{V}$ anomalies, averaged over the 100 most intense NH TCs (as in Fig. 8). Anomalies computed as in Fig. 8, but compared with the climatological (1970-99) relative monthly value, then averaged over this 20 -day period. Units are $\mathrm{cm} \mathrm{s}^{-1}$.

When the annual average OHT obtained by the simulation of the period 1970-89 with and without momentum transfer to the ocean were compared, no significant differences were found. As shown in Fig. 12, the difference between the OHT obtained in the two simulations is within the range of one standard deviation (gray shaded) of the annual OHT time series.

\section{d. Impact of global warming on TC activity and TC air-sea interaction}

A scenario simulation of the twenty-first century has been performed forcing the model with the GHG concentration prescribed, according to the $\mathrm{A} 1 \mathrm{~B}$ emission scenario described in section 2. In terms of concentration, in year 2069 the $\mathrm{CO}_{2}$ is doubled with respect to the year 1950 value (Fig. 1, dotted-dashed line). By 204069 , the global mean temperature at the earth's surface is about $1.9^{\circ} \mathrm{C}$ warmer than the mean obtained for the period 1950-70 (Fig. 1, solid line). During the last part of the simulation [2040-69 (21C)], the $\mathrm{CO}_{2}$ concentration is $70 \%$ higher than the $20 \mathrm{C}$ mean value and a warming ranging from $1^{\circ}$ to $2^{\circ} \mathrm{C}$ affects the tropics in JJASO and DJFMA, respectively (Fig. 13). The largest warming occurs on the northeastern part of the basins and along the equator in the Pacific basin during JJASO (Fig. 13, left panel). A similar warming pattern is evident in
DJFMA (Fig. 13, right panel). Also during this period, the southwestern tropical Pacific basin and the tropical southern Indian basin appear to be about $1.5^{\circ} \mathrm{C}$ warmer than in the reference period.

The SST plays a role in TC genesis (Peterson and Baringer 2009) and many studies (e.g., Bengtsson et al. 1996; Royer et al. 1998; Sugi et al. 2002; McDonald et al. 2005; Yoshimura et al. 2006; Landsea 2007; Knutson et al. 2008, 2010a,b) suggest that in a warmer climate, there might be changes in TC frequency, and the vast majority of climate models suggest decreases in global tropical cyclone numbers (Knutson et al. 2010a).

Despite the evident signature in tropical SST warming under the twenty-first-century scenario (Fig. 13), CMCC MED does not exhibit significant changes between 20C and $21 \mathrm{C}$ in the annual number of detected TCs in both the hemispheres (Fig. 14, top panel), as confirmed by counting the TCs annual number region by region (regions defined as in section 3). This result disagrees with previous findings obtained with a similar coupled model (described in Gualdi et al. 2008), where it was found that a warmer climate leads to a reduction of the TC numbers. Further work is needed to clarify whether this discrepancy is related to the lower $\mathrm{CO}_{2}$ increment featured in the $21 \mathrm{C}$ experiment, with respect to the $2 \mathrm{xCO} 2$ experiment in Gualdi et al. (2008) or to a different model response. An 


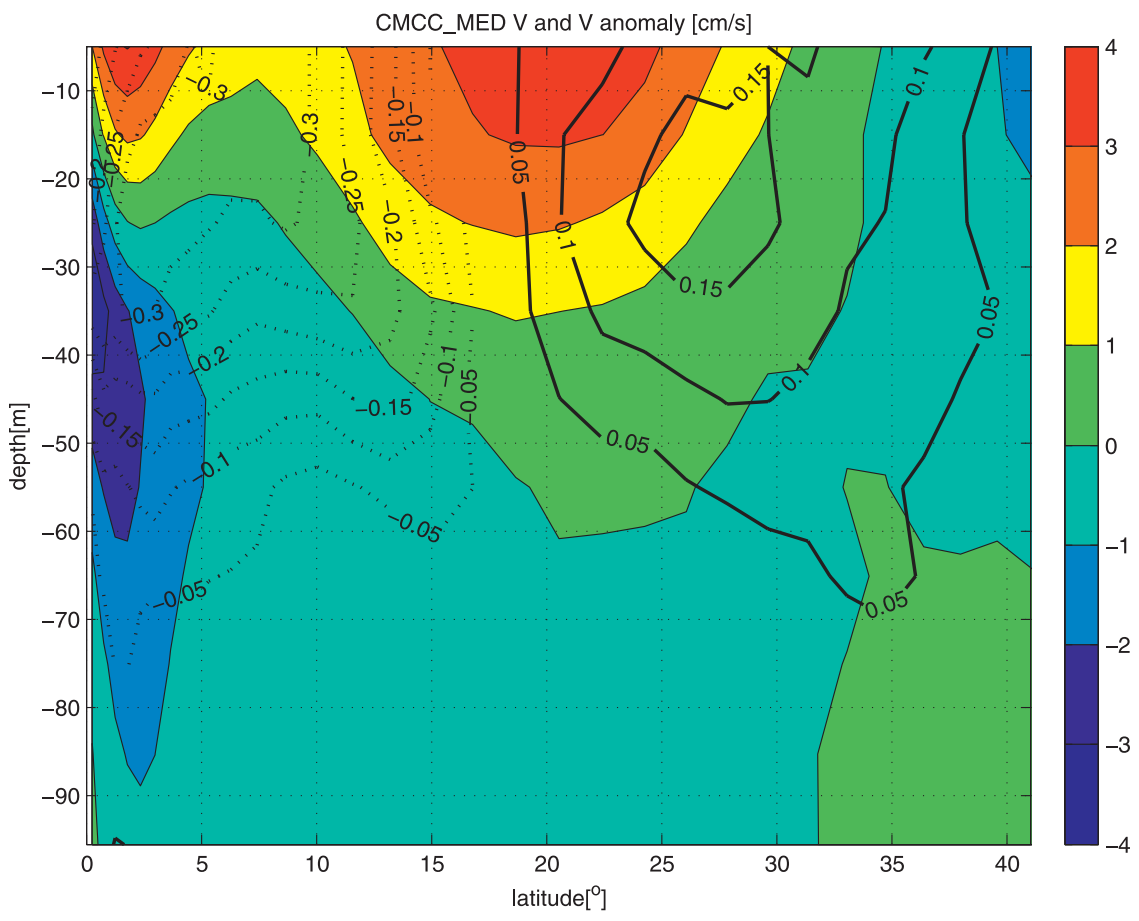

FIG. 10. Zonally averaged meridional $\mathbf{V}$ mean computed over the period JJASOND 1970-99 (color) and TC-induced meridional $\mathbf{V}$ anomalies, averaged over the 100 most intense NH TCs computed for the same period. Anomalies computed as in Fig. 9. Units are $\mathrm{cm} \mathrm{s}^{-1}$.

additional 2xCO2 experiment using CMCC_MED should be analyzed.

The possible changes of TC intensity, due to global climate warming, have been deeply investigated during the past years (e.g., Walsh and Ryan 2000; Knutson et al. 2001; Webster et al. 2005; Trenberth 2005; Emanuel 2005; Oouchi et al. 2006; Vecchi and Soden 2007a,c; Elsner et al. 2008; Emanuel et al. 2008; Bender et al. 2010). A broad consensus is that under a warmer climate, the higher energy available from a warmer ocean and changes in the mean thermodynamic state of the tropical atmosphere will lead to an increase in the upper limits of the distribution of tropical cyclone intensities (Knutson et al. 2010a).

To understand the potential TC intensity changes under different climate conditions in the model, the power dissipation index (PDI; Emanuel 2005) has been calculated. The yearly accumulated NH and SH PDI time series along the 120 simulated years (Fig. 14, bottom panel) does not show any trend, and the same result is obtained when computing the PDI time series region by region. This result indicates that in our model, the energy associated with the TC activity does not change. Also, the changes in precipitation and $10-\mathrm{m}$ wind patterns associated with the 100 most intense TCs during $21 \mathrm{C}$ are found to not be significantly different than the same patterns calculated over 20C (Fig. 6). Thus, changes in atmospheric forcings, following the A1B scenario until 2069, do not appear to significantly affect the frequency and intensity of the simulated TCs.

Consistent with the results obtained by other coupled GCMs (Guilyardi 2006; Meehl et al. 2006), the present model shows a weakening of the trade winds under warmer conditions $(21 \mathrm{C})$, linked to a weakening of the tropical circulation, as suggested by Vecchi and Soden (2007b). The simulated zonal wind component (U), averaged in longitude for the JJASOND 21C, is systematically weaker (up to $30 \%$ at $5^{\circ} \mathrm{N}$ ) from the equator to $30^{\circ} \mathrm{N}$ if compared to the one computed over the JJASOND 20C (not shown). During 21C, the model shows the same coherence between the $\mathrm{OHT}_{\mathrm{TC}}$ and $\mathrm{TAUX}_{\mathrm{TC}}$ anomalies found in $20 \mathrm{C}$, and despite the described weakening of the trade winds under warmer conditions, there are no significant differences in the amplitude of the $\mathrm{OHT}_{\mathrm{TC}}$ and $\mathrm{TAUX}_{\mathrm{TC}}$ anomalies computed over the two periods. The statistical significance is verified at the $95 \%$ level with a bootstrap method.

\section{Discussion and conclusions}

The ocean heat transport is a major driver of the climate system. Thus, understanding the interplay between TCs and the upper ocean is crucial to clarifying their role in the dynamics of the global climate. In this work we 


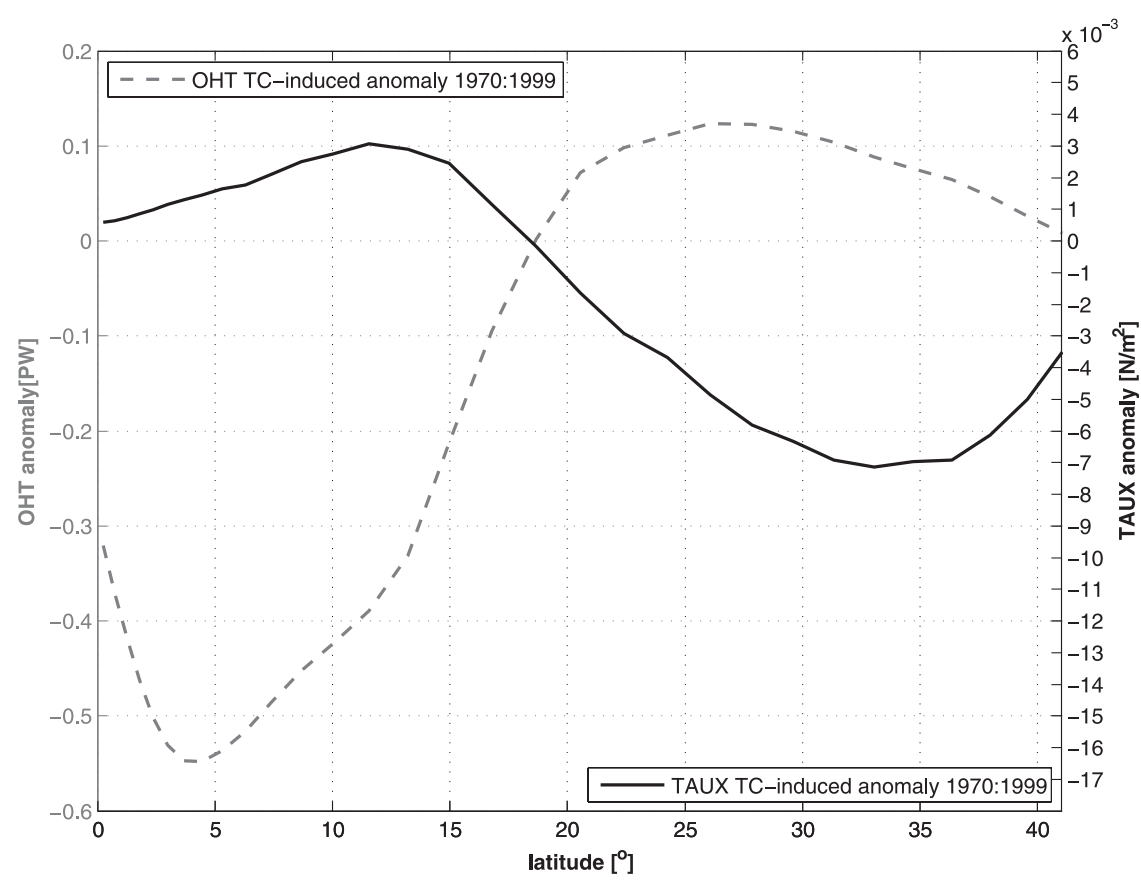

FIG. 11. NH OHT Anomaly induced by TCs (gray dashed, as in Fig. 7) and NH TAUX anomaly (black solid).

report on the effect of tropical cyclones on the Northern Hemisphere ocean heat transport process.

A novel approach based on composite analysis over the TC events is used to show the short-term effect (order of weeks) of TCs on the OHT, whereas the current debate focuses on the longer-term effect. To address this issue, we compared results from a fully coupled experiment with an additional simulation where the TC effect on the momentum flux at the ocean surface was removed.

The model used is a state-of-the-art fully coupled climate model that displays an improved representation of tropical cyclone-like vortices, compared with previous CGCMs. However, the TCs counting over the Atlantic and eastern North Pacific regions is still underestimated, and this may in turn affect, through the spatial variability in ocean mixing (Boos et al. 2004), the correct representation of TC-ocean interaction over these two regions. We are confident that this underestimation does not hamper our main conclusions on the global OHT.

The model results show that tropical and subtropical OHT is modulated by TC activity mainly through a surface wind-driven circulation, and this is consistent with the finding that shallow-water circulation dominates the poleward OHT (Boccaletti et al. 2005). This effect significantly increases the poleward OHT out of the tropics, as suggested by Emanuel (2001), and also increases the heat transport into the deep tropics, in accordance with the results of Jansen and Ferrari (2009).
The magnitude of the TC-induced OHT anomaly is stronger on the equatorward side of the subtropical cell.

The detected TC-induced wind stress anomalies over the $\mathrm{NH}$ tropical belt can be visualized as the net effect of the Ekman transport induced by a big single compositeTC-like perturbation, resulting from the combination in space and time of the individual TCs, over the considered period. This idealized large and strong cyclonic perturbation, crossing the $\mathrm{NH}$ tropics, reinforces the trade winds at higher latitudes $\left(18^{\circ}-30^{\circ} \mathrm{N}\right.$ band) and weakens them at lower latitudes $\left(5^{\circ}-18^{\circ} \mathrm{N}\right.$ band). The modeled $\mathrm{OHT}_{\mathrm{TC}}$ anomaly is likely to be an underestimate of what is expected in the real world, since the magnitude of the strongest model TC (category 1 hurricanes) is about $50 \%$ weaker than what is observed (category 5 hurricanes). Thus, the model suggests that TCs significantly affect the OHT on weekly time scales. However, the induced perturbation does not seem to impact the yearly averaged large-scale meridional heat advection, as revealed by the comparison between two simulations performed over $1970-89$ period with and without TCs effect on the momentum at the surface of the ocean. This result is in accord with the findings of Jansen et al. (2010). We might speculate that the heat anomalies below the mixed layer induced by TCs do not propagate in the climatology.

Under warmer conditions (21C), TC activity (frequency and intensity) and the $\mathrm{OHT}_{\mathrm{TC}}$ anomaly are not 


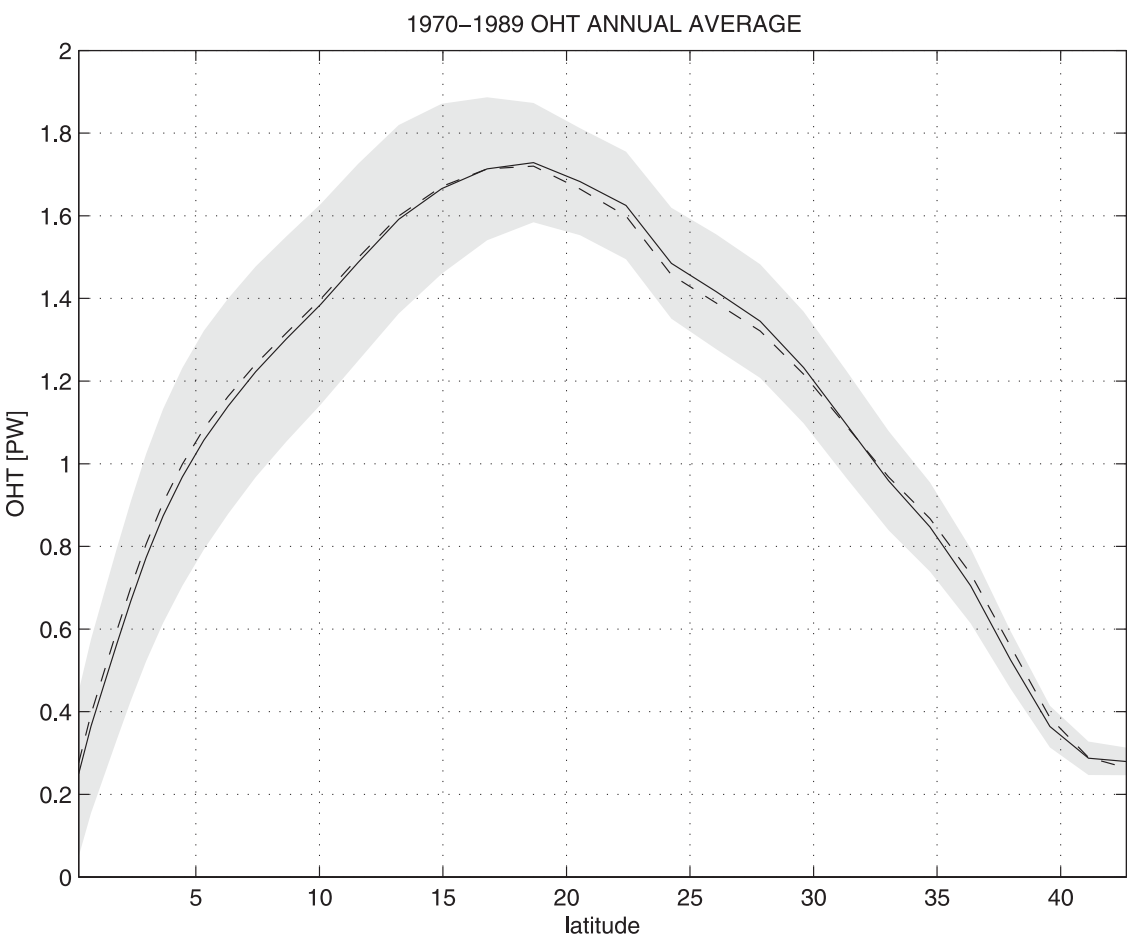

FIG. 12. NH OHT averaged over the period $1970-89$ as obtained by the simulation with (solid line) and without (dashed line) the effect of TCs on the momentum at the surface of the ocean. Gray region indicates \pm 1 standard deviation from the solid line. Units are PW.

significantly changed if compared to the twentieth century (20C).

This work suggests that a climate control role for TCs (Emanuel 2001; Sriver and Huber 2007; Pasquero and Emanuel 2008; Hu and Meehl 2009) can be investigated by a state-of-the-art coupled GCM, at least in terms of induced OHT.

The displayed CMCC_MED skill in representing $\mathrm{TC}$ interaction with climate and the presence of a high-resolution Mediterranean Sea model in the coupled system pose a promising basis to explore the interactions between TC activity and the Mediterranean environment (Krichak et al. 2007) and also to the study of subsynoptic-scale vortices generated over sea (Claud et al. 2010). This will be the subject of future work.

Recent results (Murakami and Sugi 2010) show that high resolution is generally desirable for accurate projections of TC intensity and temporal variations in TC

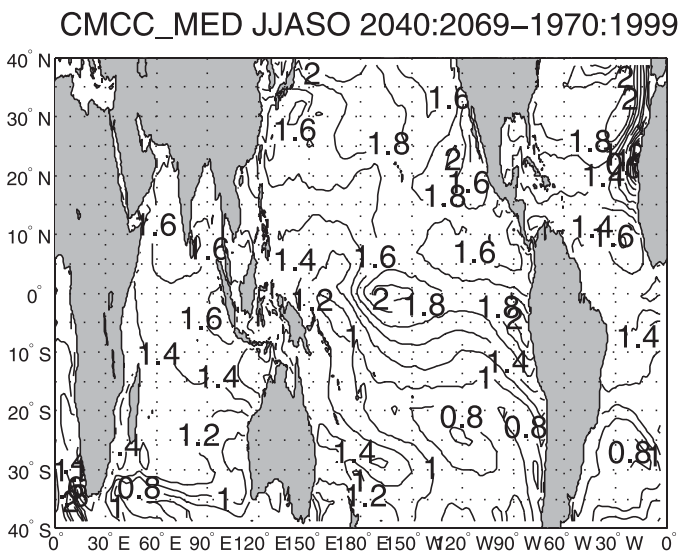

CMCC MED DJFMA 2040:2069-1970:1999

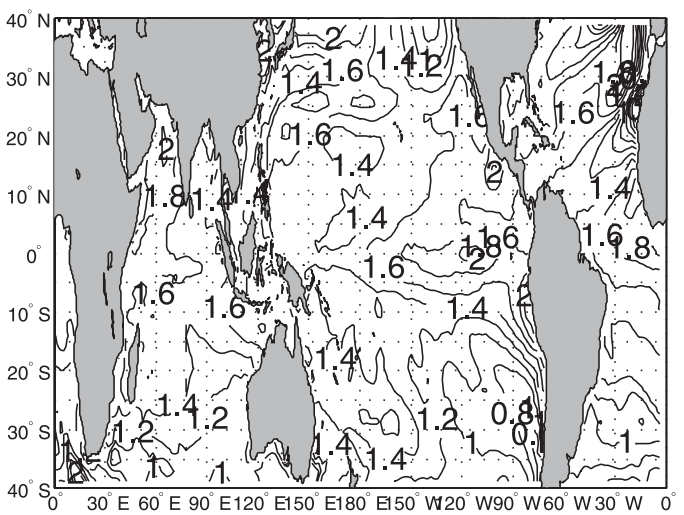

FIG. 13. Seasonal means of SST differences as obtained from the model in 2040-69 with respect to 1970-99 for (left) JJASO and (right) DJFMA. Contours are $0.2^{\circ}$ from $0^{\circ}$ to $2^{\circ} \mathrm{C}$ 

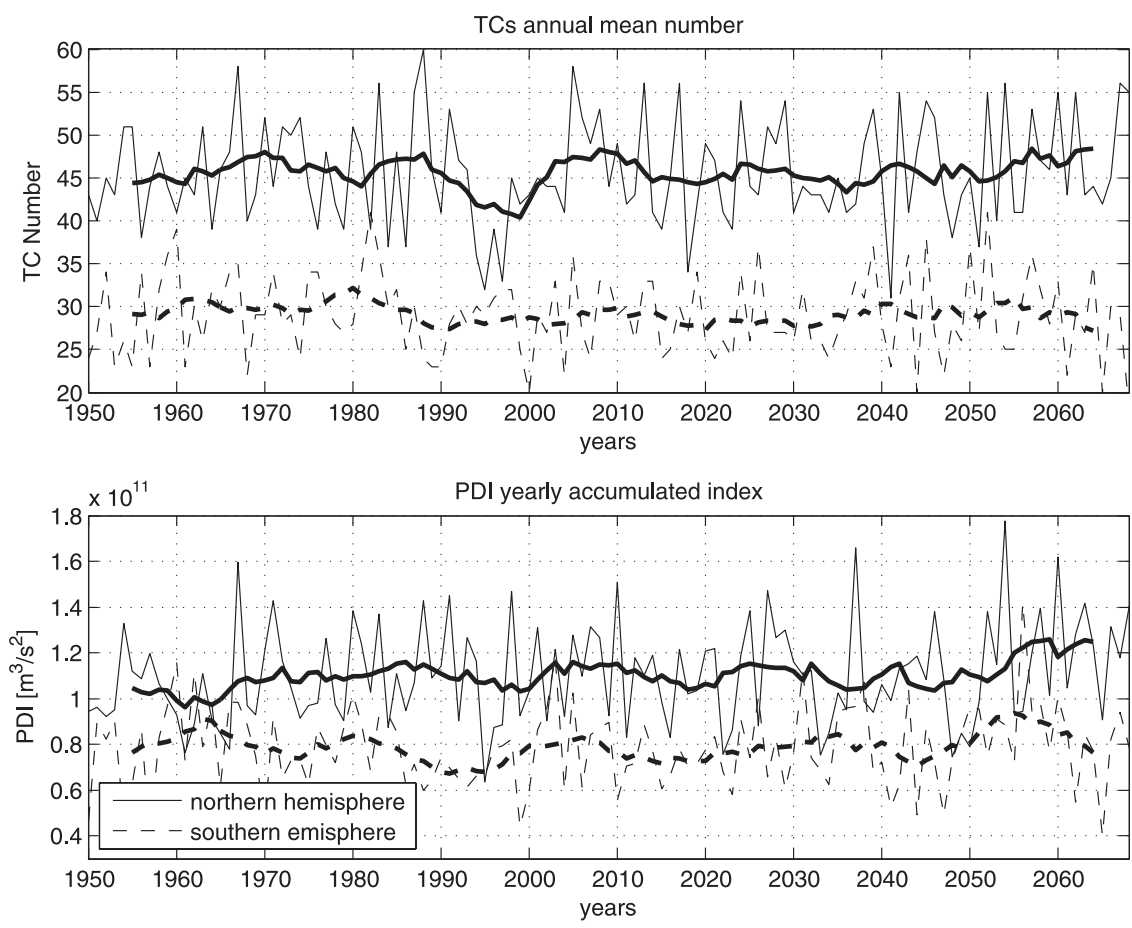

FIG. 14. (top) TC numbers time series and (bottom) PDI, for the 1950-2069 period following 20C3M and A1B scenario. Solid lines represent NH, and dashed lines represent SH. Bold line indicates the 11-yr running mean.

genesis. This issue will be further explored in the future, by using a higher-resolution version of CMCC_MED.

Acknowledgments. The authors are grateful to Erich Roeckner for his helpful comments. The CSIRO code for TC detection was provided by the TCMIP, whose leader (Kevin Walsh) assistance is gratefully acknowledged. This work was supported by the CIRCE project, founded by the European Commission's Sixth Framework Programme through Contract 036961; by Centro EuroMediterraneo per i Cambiamenti Climatici (CMCC); and by the cooperation of Italy-SIDS (Small Island Developing States) on the impacts of climate change and on the policies of the reduction of greenhouse gases.

\section{REFERENCES}

Bellucci, A., S. Gualdi, E. Scoccimarro, and A. Navarra, 2008: NAO-ocean circulation interactions in a coupled general circulation model. Climate Dyn., 31, 759-777, doi:10.1007/ s00382-008-0408-4.

Bender, M. A., and I. Ginis, 2000: Real-case simulations of hurricaneocean interaction using a high-resolution coupled model: Effects on hurricane intensity. Mon. Wea. Rev., 128, 917-946.

_ - _ , and Y. Kurihara, 1993: Numerical simulations of tropical cyclone-ocean interaction with a high-resolution coupled model. J. Geophys. Res., 98, 23 245-23 263.
, T. R. Knutson, R. E. Tuleya, J. J. Sirutis, G. A. Vecchi, S. T. Garner, I. M. Held, 2010: Modeled impact of anthropogenic warming of the frequency of intense Atlantic hurricanes. Science, 327, 454-458.

Bengtsson, L., M. Botzet, and M. Esch, 1995: Hurricane-type vortices in a general circulation model. Tellus, 47A, 175-196.

$\longrightarrow, \ldots$, and -1996 : Will greenhouse gas-induced warming over the next 50 years lead to higher frequency and greater intensity of hurricanes? Tellus, 48A, 57-73.

Black, P. G., 1983: Ocean temperature change induced by tropical cyclones. Ph.D. dissertation, Pennsylvania State University, 278 pp.

Boccaletti, G., R. Ferrari, A. Adcroft, D. Ferreira, and J. Marshall, 2005: The vertical structure of ocean heat transport. Geophys. Res. Lett., 32, L10603, doi:10.1029/2005GL022474.

Boos, W. R., J. R. Jeffey, R. Scott, and K. A. Emanuel, 2004: Transient diapycnal mixing and the meridional overturning circulation. J. Phys. Oceanogr., 34, 334-341.

Camargo, S. J., A. G. Barnston, and S. E. Zebiak, 2004: Properties of tropical cyclones in atmospheric general circulation models. IRI Tech. Rep. 04-02, 72 pp.

Chan, J. C. L., Y. Duan, and L. K. Shay, 2001: Tropical cyclone intensity change from a simple ocean-atmosphere coupled model. J. Atmos. Sci., 58, 154-172.

Chang, S. W., and F. A. Anthes, 1979: The mutual response of the tropical cyclone and the ocean. J. Phys. Oceanogr., 9, 128-135.

Chauvin, F., J.-F. Royer, and M. Déqué, 2006: Response of hurricanetype vortices to global warming as simulated by ARPEGEClimat at high resolution. Climate Dyn., 27, 377-399.

Claud, C., B. Alhammoud, B. M. Funatsu, and J.-P. Chaboureau, 2010: Mediterranean hurricanes: Large-scale environment and 
convective and precipitating areas from satellite microwave observations. Nat. Hazard. Earth Syst. Sci., 10, 2199-2213.

Elsner, J. B., P. Kossin, and T. H. Jagger, 2008: The increasing intensity of the strongest tropical cyclones. Nature, 455, 92-95.

Emanuel, K. A., 2001: Contribution of tropical cyclones to meridional heat transport by the oceans. J. Geophys. Res., 106 (D14), 14 771-14 781.

, 2003: Tropical cyclones. Annu. Rev. Earth Planet. Sci., 31, 75-104.

- 2005: Increasing destructiveness of tropical cyclones over the past 30 years. Nature, 436, 686-688.

_ , R. Sundararajan, and J. Williams, 2008: Hurricanes and global warming: Results from downscaling IPCC AR4 simulations. Bull. Amer. Meteor. Soc., 89, 347-367.

Fedorov, A. V., C. M. Brierley, and K. Emanuel, 2010: Tropical cyclones and permanent El Niño in the early Pliocene epoch. Nature, 463, 1066-1070.

Fichefet, T., and M. A. Morales-Maqueda, 1999: Modeling the influence of snow accumulation and snow-ice formation on the seasonal cycle of the Antarctic sea-ice cover. Climate Dyn., 15, 251-268.

Fogli, P. G., and Coauthors, 2009: INGV-CMCC Carbon (ICC): A carbon cycle earth system model. CMCC Tech. Rep. 61, 30 pp.

Gent, P. R., and J. C. McWilliams, 1990: Isopycnal mixing in ocean circulation models. J. Phys. Oceanogr., 20, 150-155.

Gray, W. M., 1979: Hurricanes: Their formation, structure and likely role in the tropical circulation. Meteorology Over the Tropical Oceans, D. B. Shaw, Ed., Royal Meteorological Society, 155-218.

Gualdi, S., E. Scoccimarro, and A. Navarra, 2008: Changes in tropical cyclone activity due to global warming: Results from a high-resolution coupled general circulation model. J. Climate, 21, 5204-5228.

Guilyardi, E., 2006: El Niño-mean state-seasonal cycle interactions in a multi-model ensemble. Climate Dyn., 26, 329-348.

$\mathrm{Hu}$, A., and G. A. Meehl, 2009: Effect of the Atlantic hurricanes on the oceanic meridional overturning circulation and heat transport. Geophys. Res. Lett., 36, L03702, doi:10.1029/2008GL036680.

Jansen, M., and R. Ferrari, 2009: Impact of the latitudinal distribution of tropical cyclones on ocean heat transport. Geophys. Res. Lett., 36, L06604, doi:10.1029/2008GL036796.

$\_,-$, and T. A. Mooring, 2010: Seasonal versus permanent thermocline warming by tropical cyclones. Geophys. Res. Lett., 37, L03602, doi:10.1029/2009GL041808.

Kleinschmidt, E., Jr., 1951: Grundlagen einer theorie der tropischen zyklonen. Arch. Meteor. Geophys. Bioklimatol., 4A, 53-72.

Knutson, T. R., R. E. Tuleya, W. Shen, and I. Ginis, 2001: Impact of $\mathrm{CO}_{2}$-induced warming on hurricane intensities as simulated in a hurricane model with ocean coupling. J. Climate, 14, 24582468.

— J. J. Sirutis, S. T. Garner, G. A. Vecchi, and I. M. Held, 2008: Simulated reduction in Atlantic hurricane frequency under twenty-first-century warming conditions. Nat. Geosci., 1, 359-364.

— , and Coauthors, 2010a: Tropical cyclones and climate change. Nat. Geosci., 3, 157-163, doi:10.1038/NGEO779.

_ C. C. Landsea, and K. Emanuel, 2010b: Tropical cyclones and climate change: A review. Global Perspectives on Tropical Cyclones, J. C. L. Chan and J. Kepert, Eds., World Scientific, 243-286.

Krichak, S. O., P. Alpert, and M. Dayan, 2007: An evaluation of the role of Hurricane Olga (2001) in an extreme rainy event in Israel using dynamic tropopause maps. Meteor. Atmos. Phys., 98, 35-53, doi:10.1007/s00703-006-0230-7.
Landsea, C. W., 2007: Counting Atlantic tropical cyclones back to 1900. Eos, Trans. Amer. Geophys. Union, 88, 197-202.

Lin, S. J., and R. B. Rood, 1996: Multidimensional flux form semiLagrangian transport. Mon. Wea. Rev., 124, 2046-2068.

Liu, L. L., W. Wang, and R. X. Huang, 2008: The mechanical energy input to the ocean induced by tropical cyclones. J. Phys. Oceanogr., 38, 1253-1266.

Madec, G., 2008: NEMO ocean engine, version 3.0. IPSL Note du Pôle de Modélisation 27, 209 pp.

_, P. Delecluse, M. Imbard, and C. Lévy, 1998: OPA 8.1 ocean general circulation model reference manual. IPSL Note du Pôle de Modélisation 11, 91 pp.

McDonald, R. E., D. G. Bleaken, D. R. Cresswell, V. D. Pope, and C. A. Senior, 2005: Tropical storms: Representation and diagnosis in climate models and the impacts of climate change. Climate Dyn., 25, 19-36, doi:10.1007/s00382-004-0491-0.

Meehl, G. A., H. Teng, and G. Branstator, 2006: Future changes of El Niño in two global coupled climate models. Climate Dyn., 26, 549-566.

Murakami, H., and M. Sugi, 2010: Effect of model resolution on tropical cyclone climate projections. SOLA, 6, 73-76.

National Weather Service, 2002: Tropical cyclone definitions. NWSM 10-604, 10 pp. [Available online at http://www.weather. gov/directives/010/archive/pd01006004a.pdf.]

Nordeng, T. E., 1994: Extended versions of the convective parametrization scheme at ECMWF and their impact on the mean and transient activity of the model in the tropics. ECMWF Research Department Tech. Memo. 206, 41 pp.

Oddo, P., M. Adani, N. Pinardi, C. Fratianni, and D. Pettenuzzo, 2009: Nested Atlantic-Mediterranean sea general circulation model for operational forecasting. Ocean Sci., 5, 461473.

Oouchi, K., J. Yoshimura, H. Yoshimura, R. Mizuta, S. Kusunoki, and N. A. Noda, 2006: Tropical cyclone climatology in a global-warming climate as simulated in a $20 \mathrm{~km}$-mesh global atmospheric model: Frequency and wind intensity analyses. J. Meteor. Soc. Japan, 84, 259-276.

Pasquero, C., and K. Emanuel, 2008: Tropical cyclones and transient upper-ocean warming. J. Climate, 21, 149-162.

Peterson, T. C., and M. O. Baringer, Eds., 2009: State of the climate in 2008. Bull. Amer. Meteor. Soc., 90 (8), S1-S196.

Pezza, A. B., and I. Simmonds, 2005: The first South Atlantic hurricane: Unprecedented blocking, low shear and climate change. Geophys. Res. Lett., 32, L15712, doi:10.1029/ 2005GL023390.

Price, J. F., 1981: Upper ocean response to a hurricane. J. Phys. Oceanogr., 11, 153-175.

Randall, D. A., and Coauthors, 2007: Climate models and their evaluation. Climate Change 2007: The Physical Science Basis, S. Solomon et al., Eds., Cambridge University Press, 589-662.

Rayner, N. A., D. E. Parker, E. B. Horton, C. K. Folland, L. V. Alexander, D. P. Rowell, E. C. Kent, and A. Kaplan, 2003: Global analyses of sea surface temperature, sea ice, and night marine air temperature since the late nineteenth century. J. Geophys. Res., 108, 4407, doi:10.1029/2002JD002670.

Riehl, H., 1950: A model of hurricane formation. J. Appl. Phys., 21, 917-925.

Roeckner, E., and Coauthors, 2003: The atmospheric general circulation model ECHAM5. Part I: Model description. MPI Rep. 349, 127 pp.

, and Coauthors, 2006: Sensitivity of simulated climate to horizontal and vertical resolution in the ECHAM5 atmosphere model. J. Climate, 19, 3771-3791. 
Roullet, G., and G. Madec, 2000: Salt conservation, free surface, and varying levels: A new formulation for ocean general circulation models. J. Geophys. Res., 105, 23 927-23 942.

Royer, J.-F., F. Chauvin, B. Timbal, P. Araspin, and D. Grimal, 1998: A GCM study of the impact of greenhouse gas increase on the frequency of occurrence of tropical cyclones. Climate Dyn., 38, 307-343.

Schade, L. R., and K. A. Emanuel, 1999: The ocean's effect on the intensity of tropical cyclones: Results from a simple coupled atmosphere-ocean model. J. Atmos. Sci., 56, 642-651.

Sriver, R. L., 2010: Climate change: Tropical cyclones in the mix. Nature, 463, 1032-1033.

— , and M. Huber, 2007: Observational evidence for an ocean heat pump induced by tropical cyclones. Nature, 447, 577-580, doi: $10.1038 /$ nature 05785 .

$\longrightarrow$, and — 2010: Modeled sensitivity of upper thermocline properties to tropical cyclone winds and possible feedbacks on the Hadley circulation. Geophys. Res. Lett., 37, L08704, doi:10.1029/2010GL042836.

Sugi, M., A. Noda, and N. Sato, 2002: Influence of global warming on tropical cyclone climatology: An experiment with the JMA global model. J. Meteor. Soc. Japan, 80, 249-272.

Sutyrin, G. G., and A. P. Khain, 1979: Interaction of the ocean and the atmosphere in the area of moving tropical cyclone. Dokl. Akad. Nauk SSSR, 249, 467-470.

Tiedtke, M., 1989: A comprehensive mass flux scheme for cumulus parametrization in large-scale models. Mon. Wea. Rev., 117, 1779-1800.

Trenberth, K., 2005: Uncertainty in hurricanes and global warming. Science, 308, 1753-1754.

— and ocean heat transports. J. Climate, 14, 3433-3443.

Valcke, S., Ed., 2006: OASIS3 user guide (prism_2-5). PRISMSupport Initiative Rep. 3, 64 pp.
Vecchi, G. A., and B. J. Soden, 2007a: Effect of remote sea surface temperature change on tropical cyclone potential intensity. Nature, 450, 1066-1070.

— and $-2007 \mathrm{~b}$ : Global warming and the weakening of the tropical circulation. J. Climate, 20, 4316-4340.

$\longrightarrow$, and — 2007c: Increased tropical Atlantic wind shear in model projections of global warming. Geophys. Res. Lett., 34, L08702, doi:10.1029/2006GL028905.

Vichi, M., E. Manzini, P. G. Fogli, A. Alessandri, L. Patara, E. Scoccimarro, S. Masina, and A. Navarra, 2011: Global and regional ocean carbon uptake and climate change: Sensitivity to a substantial mitigation scenario. Climate Dyn., doi:10.1007/ s00382-011-1079-0, in press.

Walsh, K. J. E., 1997: Objective detection of tropical cyclones in high-resolution analyses. Mon. Wea. Rev., 125, 958-977.

— and B. F. Ryan, 2000: Tropical cyclone intensity increase near Australia as a result of climate change. J. Climate, 13, 3029-3036.

—, M. Fiorino, C. W. Landsea, and K. L. McInnes, 2007: Objectively determined resolution-dependent threshold criteria for the detection of tropical cyclones in climate models and reanalyses. J. Climate, 20, 2307-2314.

Webster, P. J., G. J. Holland, J. A. Curry, and H.-R. Chang, 2005: Changes in tropical cyclones number, duration and intensity in a warming environment. Science, 309, 1844-1846.

Willoughby, H. E., J. A. Clos, and M. G. Shoreibah, 1982: Concentric eye walls, secondary wind maxima, and the evolution of the hurricane vortex. J. Atmos. Sci., 39, 395-411.

Xie, P., and P. Arkin, 1997: Global precipitation: A 17-year monthly analysis based on gauge observations, satellite estimates, and numerical model outputs. Bull. Amer. Meteor. Soc., 78, 2539-2558.

Yoshimura, J., M. Sigu, and A. Noda, 2006: Influence of greenhouse warming on tropical cyclone frequency. J. Meteor. Soc. Japan, 84, 405-428. 